\title{
Genome Resource for Peanut Web Blotch Causal Agent Peyronellaea arachidicola Strain YY187
}

\author{
Shaojian Li, ${ }^{1}$ Xia Xue, ${ }^{2}$ Meng Gao, ${ }^{1}$ Na Wang, ${ }^{1}$ Xiaowei Cui, ${ }^{1}$ Suling Sang, ${ }^{1}$ Wanwan Fan, \\ and Zhenyu Wang ${ }^{1, \dagger}$ \\ ${ }^{1}$ Institute of Plant Protection, Key Laboratory of Integrated Pest Management on Crops in Southern Region \\ of North China; Henan Key Laboratory of Crop Pest Control; International Joint Research Laboratory for \\ Crop Protection of Henan, Henan Academy of Agricultural Sciences, Zhengzhou 450002, China \\ ${ }^{2}$ Precision Medicine Center, Academy of Medical Sciences, Zhengzhou University, Zhengzhou 450052, China
}

\begin{abstract}
Peyronellaea arachidicola is the causal agent of peanut (Arachis hypogaea L.) web blotch. Here, we report an assembled draft genome sequence of $P$. arachidicola strain YY187 obtained from the symptomatic leaf of peanut in China. The genome size is $47.3 \mathrm{Mb}$, consisting of 26 contigs $\left(\mathrm{N}_{50}=2.2 \mathrm{Mb}\right)$ with $\mathrm{G}+\mathrm{C}$ content of $56.37 \%$. This genome will provide a valuable foundation for further research on genetics and comparative genomics of $P$. arachidicola.
\end{abstract}

\section{Genome Announcement}

Peanut web blotch, caused by Peyronellaea arachidicola (also known as Didymella arachidicola or Phoma arachidicola) (Aveskamp et al. 2010; Chen et al. 2015; Marasas et al. 1974; Tomilin 1979), is one of the most important foliar fungal diseases of peanut in China (Cui et al. 2016; Li et al. 2018). Peanut web blotch was first reported in Texas, U.S.A., in 1972 (Pettit et al. 1986) and then found in Liaoning, Shandong, Shaanxi, and Henan provinces of China during the 1980s to 1990s (Fu et al. 2013). Web blotch lesions are characterized as having a net-like webbing pattern, brown to tan in color, which typically grow together to cover the entire leaf in the later stage. This disease occurs at all growth stages of peanut and results in significant yield losses of up to $30 \%$ (Xu et al. 1995). Past studies focused on the epidemic dynamics and management practices of peanut web blotch (Cui et al. 2016; Fu et al. 2013; Lancaster et al. 2005; Taber et al. 1984; Van Wyk et al. 1987), while little is known about the biology of the causal agent $P$. arachidicola on the genomic level. In this study, we report the first draft genome sequence of $P$. arachidicola strain YY187, providing a valuable resource for understanding the genetic diversity and further comparative genomics of the fungal pathogen.

YY187 was isolated from symptomatic leaves of peanut (Arachis hypogaea L.) collected from Yuanyang, Henan Province, China, in September 2015. Genomic DNA was extracted from mycelia by using the DNeasy plant mini kit (QIAGEN). Genomic DNA was quantified by a NanoDrop spectrophotometer 2000c and Qubit Fluorometer (Thermo Fisher Scientific Inc.). SMRT bell libraries were constructed and sequenced on the PacBio Sequel platform (Pacific Biosciences) using SMRT cells.

A total of $7.86 \mathrm{~Gb}$ filtered subreads with average length of $8.09 \mathrm{~kb}$ were generated from PacBio Sequel sequencing. PacBio polymerase reads were processed by SMRT analysis package version 2.3.0 to filter out reads with quality less than 0.8 , to remove adapters and to

${ }^{\dagger}$ Corresponding author: Z. Y. Wang; wangzy21@163.com

S. J. Li and X. Xue contributed equally to this work.

The author(s) declare no conflict of interest.

Accepted for publication 11 August 2020.
Funding

This work was funded by the National Key R\&D Program of China (2018YFD0201008).

\section{Keywords}

Peyronellaea arachidicola, peanut web blotch, genome 
Table 1. Summary statistics of the draft genome assembly of Peyronellaea arachidicola

\begin{tabular}{lc} 
Features & Numbers \\
Genome size $(\mathrm{Mb})$ & 47.3 \\
Number of contigs & 26 \\
Max. contig length $(\mathrm{kb})$ & $6,557.3$ \\
Contig N & 2.2 \\
Contig No $(\mathrm{Mb})$ & 1.4 \\
$\mathrm{G}+\mathrm{C}$ content $(\%)$ & 56.4 \\
Number of predicted genes & 17,447 \\
\hline
\end{tabular}

extract subreads with length of at least $1,000 \mathrm{bp}$. The de novo genome assembly was generated by merging a Canu 1.5 (Koren et al. 2017) assembly with a Wtdbg 2.2 (Ruan and Li 2020) assembly using Quickmerge 0.2 (Chakraborty et al. 2016). The Arrow correction was performed by using SMRT Link 5.0 (Pacific Biosciences). Genome completeness (complete BUSCOs $=98.6 \%$ ) and assembly quality were assessed using BUSCO 2.0 (Simão et al. 2015; Waterhouse et al. 2017). The size of the $P$. arachidicola genome was $47.3 \mathrm{Mb}$, consisting of 26 contigs with $\mathrm{N}_{50}$ of $2.2 \mathrm{Mb}$ with a $\mathrm{G}+\mathrm{C}$ content of $56.4 \%$ (Table 1). The functional genes were predicted by Genscan 1.0 (Burge and Karlin 1997), Augustus 2.4 (Stanke and Waack 2003), GlimmerHMM 3.0.4 (Majoros et al. 2004), GenelD 1.4 (Blanco et al. 2007), and SNAP (2006-07-28) (Korf 2004) using the genome of Ascochyta rabiei strain ArDII as a reference (GenBank accession no. GCA_001630375.1). A total of 17,447 genes (average length 1,590.28 bp), 38,508 coding sequences (CDSs, average length $657.21 \mathrm{bp}$ ), and 38,508 exons (average length $657.21 \mathrm{bp}$ ) were predicted by integrating all the above gene sets to a nonredundant gene set using EVM 1.1.1 (Haas et al. 2008).

The draft genome sequence has been deposited under BioProject PRJNA562378 and Biosample SAMN12638752. This Whole Genome Shotgun project has been deposited at DDBJ/ENA/GenBank under the accession WOCF00000000. The version described in this paper is version WOCF01000000. Data has also been deposited in the Sequence Read Archive (SRA) database, under SRA accession SRR10589210.

\section{Literature Cited}

Aveskamp, M. M., de Gruyter, J., Woudenberg, J. H. C., Verkley, G. J. M., and Crous, P. W. 2010. Highlights of the Didymellaceae: A polyphasic approach to characterise Phoma and related pleosporalean genera. Stud. Mycol. 65:1-60.

Blanco, E., Parra, G., and Guigó, R. 2007. Using geneid to identify genes. Curr. Protoc. Bioinformatics 18:4.3.1-4.3.28.

Burge, C., and Karlin, S. 1997. Prediction of complete gene structures in human genomic DNA. J. Mol. Biol. 268:78-94.

Chakraborty, M., Baldwin-Brown, J. G., Long, A. D., and Emerson, J. J. 2016. Contiguous and accurate de novo assembly of metazoan genomes with modest long read coverage. Nucleic Acids Res. 44:e147.

Chen, Q., Jiang, J. R., Zhang, G. Z., Cai, L., and Crous, P. W. 2015. Resolving the Phoma enigma. Stud. Mycol. 82:137-217.

Cui, J. C., Zhou, R. J., Fu, J. F., Xu, Z., and Xue, C. Y. 2016. Epidemic processes and yield losses of early leaf spot and web blotch of peanut occurring together in the field. Acta Phytopathol. Sin. 46:265-272.

Fu, J. F., Wang, D. Z., Zhou, R. J., Yang, F. Y., and Su, W. N. 2013. Occurrence and epidemic dynamics of peanut web blotch disease in Liaoning Province. Chin. J. Oil Crop Sci. 35:80-83.

Haas, B. J., Salzberg, S. L., Zhu, W., Pertea, M., Allen, J. E., Orvis, J., et al. 2008. Automated eukaryotic gene structure annotation using EVidenceModeler and the Program to Assemble Spliced Alignments. Genome Biol. 9:R7.

Koren, S., Walenz, B. P., Berlin, K., Miller, J. R., Bergman, N. H., and Philippy, A. M. 2017. Canu: scalable and accurate long-read assembly via adaptive $k$-mer weighting and repeat separation. Genome Res. 27:722-736.

Korf, I. 2004. Gene finding in novel genomes. BMC Bioinformatics 5:59.

Lancaster, S. H., Jordan, D. L., York, A. C., Wilcut, J. W., Brandenburg, R. L., and Monks, D. W. 2005. Interactions of late-season morningglory (Ipomoea spp.) management practices in peanut (Arachis hypogaea). Weed Technol. 19: 803-808.
Li, S. J., Gao, M., Wang, N., Cui, X. W., Liu, C. Y., and Wang, Z. Y. 2018. Different lesion types of peanut web blotch and virulence differences of their pathogens. Plant Prot. 44:150-155.

Majoros, W. H., Pertea, M., and Salzberg, S. L. 2004. TigrScan and GlimmerHMM: two open source $a b$ initio eukaryotic gene-finders. Bioinformatics 20:2878-2879.

Marasas, W. F. O., Pauer, G. D., and Boerema, G. H. 1974. A serious leaf blotch disease of groundnuts (Arachis hypogaea L.) in southern Africa caused by Phoma arachidicola sp. nov. Phytophylactica 6:195-202.

Pettit, R. E., Philley, G. L., Smith, D. H., and Taber, R. A. 1986. Peanut web blotch: II symptoms and host range of pathogen. Peanut Sci. 13:27-30.

Ruan, J., and Li, H. 2020. Fast and accurate long-read assembly with wtdbg2. Nat. Methods 17:155-158.

Simão, F. A., Waterhouse, R. M., Ioannidis, P., Kriventseva, E. V., and Zdobnov, E. M. 2015. BUSCO: assessing genome assembly and annotation completeness with single-copy orthologs. Bioinformatics 31:3210-3212.

Stanke, M., and Waack, S. 2003. Gene prediction with a hidden Markov model and a new intron submodel. Bioinformatics 19 (Suppl 2):ii215-ii225.

Taber, R. A., Pettit, R. E., and Philley, G. L. 1984. Peanut web blotch: I. Cultural characteristics and identity of causal fungus. Peanut Sci. 11:109-114.

Tomilin, B. A. 1979. Opredelitel' gribov roda Mycosphaerella Johansen. 'Nauka' Publishing House, Leningrad, USSR.

Van Wyk, R. S., De Jong, F. M., Marasas, W. F. O., and Wingfield, M. J. 1987. Ultrastructure of ascus development in the teleomorph of Phoma arachidicola. Trans. Br. Mycol. Soc. 89:260-263.

Waterhouse, R. M., Seppey, M., Simão, F. A., Manni, M., Ioannidis, P., Klioutchnikov, G., et al. 2017. BUSCO Applications from quality assessments to gene prediction and phylogenomics. Mol. Biol. Evol. 35:543-548.

Xu, X. J., Cui, F. G., Shi, Y. M., Xu, M. X., and Bi, G. J. 1995. Studies on peanut web blotch disease in China. Acta Phytophylac. Sin. 22:70-74. 